\title{
Corrosion Study of Powder-Coated Galvanised Steel
}

\author{
Manish Kumar Bhadu, Akshya Kumar Guin, Veena Singh, and Shyam K. Choudhary
}

R\&D and Scientific Services, TATA Steel Ltd., Jamshedpur 831001, India

Correspondence should be addressed to Manish Kumar Bhadu; mkbhadu@gmail.com

Received 31 December 2012; Accepted 3 February 2013

Academic Editors: C.-H. Hsu and S. Umoren

Copyright (C) 2013 Manish Kumar Bhadu et al. This is an open access article distributed under the Creative Commons Attribution License, which permits unrestricted use, distribution, and reproduction in any medium, provided the original work is properly cited.

In general, steel is protected from corrosive environments by conversion coatings, that is, phosphating, chromating, and so forth, and then followed by different layers of paints. Nowadays, strict pollution laws and regulations are creating significant challenges for coating experts to develop an environmentally friendly product. Powder coatings have demonstrated their ability as alternative to traditional solvent-borne coatings. In the present work, polyester-based two coating systems have been investigated and their performances have been evaluated for surface topographical properties by Scanning electron microscope (SEM), and energy dispersive spectrometry (EDX), accelerated corrosion resistance by salt spray test, and impedance property by electrochemical impedance spectroscopy. Coating adhesion with the steel and hardness were evaluated by bond strength, cross cut adhesion, and pencil hardness. This paper explains the results and performance of the coatings by the above two systems.

\section{Introduction}

Galvanised steel is widely used in construction, automobile, and white goods sector. Zinc coating is the most effective and economic means to protect the steel substrate exposed to atmospheric corroding environments. It protects the steel substrate by acting as a barrier against the corrosive environment and by sacrificially corroding themselves to provide cathodic protection.

Protective ability of galvanised (GI) steel may be enhanced by employing thicker zinc coatings or by painting the metallic substrate [1]. Paints improve the surface life of underlying zinc coating acting as a barrier against zinc reaction with environmental agents. Cracks, crater, and pin holes occurring in the paint are sealed by corroded zinc products. Moreover, corroded zinc products occupy a 20$25 \%$ more volume than zinc, while iron oxides (corrosion product of steel) occupy a volume several times larger than the steel; thus, expansive forces are reduced at the zinc-paint interface compared to those at the steel-paint one [2]. The main practical problem concerning painting of zinc-coated surface lies in achieving good bond strength, that is, good adhesion of polymer with GI sheet. Often adhesion looks satisfactory immediately after painting, but it prematurely degrades after water, oxygen, and other corrosive ingredients diffuse through the polymeric coating. Several pretreatment processes were reported to improve coating adhesion. The main function of pretreatment for GI steel surface is to form a very stable passive film which will enhance the adhesion with subsequent polymeric film [3]. There are a number of pretreatment processes like phosphating, chromating, and coating of rust preventing compounds by chemical and physical vapor deposition and diffusion coating, and so forth. Some of these pretreatment processes do not contain a film forming material that is, nonpriming, and hence, they should be compatible with the rest of the painting system [4]. Primers contain a film forming material and are expected to act as the anchorage of the paint system [5]. Some of these coatings are toxic and pose concerns to the environment.

Powder thermoset coatings are solvent-free and unlike the conventional liquid coatings have zero volatile organic content (VOC). Thus, they could offer the coating formulators a robust and a highly promising approach to produce eco-friendly coatings. Moreover, not only powder coatings are easier to apply than solvent-based coatings, but, they also provide a thicker and more uniform coating. If we take into account the economical advantages of powder coatings, like cost savings in water disposal, high yield, and cheap maintenance, the total operating cost of a powder application plant is lower than that of traditional solvent-based liquid paints. 


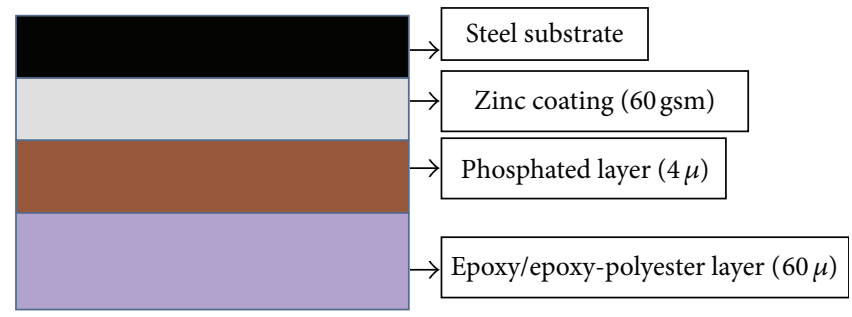

Figure 1: Schematic diagram of different coating layers with thickness.

Furthermore, a wide variety of finishes such as structured, wrinkled, metallic, and antique finishes are available with powder coatings [6-9].

Although it is possible to achieve high-gloss and smooth coatings with excellent adhesion, flexibility, and hardness by epoxy powder coating, they however exhibit poor tolerance to heat and light resulting in a pronounced tendency to fade [10]. In order to overcome this shortcoming, polyester/epoxy blends-based coating technology has been developed which shows excellent film smoothness, appropriate mechanical properties, and adherence characteristics [11]. Interestingly, blend coatings show a broader degradation temperature interval, and they volatilize to a substantially less extent compared to pure epoxy and polyester powder coating. Epoxy-polyester powder coating is a hybrid of epoxy and polyester powder coating. These hybrids have properties similar to those of epoxy powders; however, their additional advantage is that they have improved resistance to fading and improved weather resistance [11].

Hybrid powders are now regarded as the main backbone of the powder coating industry. The objective of the present work is to find out a suitable powder coating system for GI surface. A comparative study was made in between polyester and epoxy-polyester powder coating process. Adhesion on GI steel was assessed by suitable standardized adhesion tests. Anticorrosive behaviour was evaluated by salt spray and electrochemical impedance spectroscopy (EIS) method.

\section{Experimental Details}

Zero-spangle GI $\left(120 \mathrm{~g} / \mathrm{m}^{2}\right)$ sheet was used as the base substrate. These sheets were degreased to remove oil and grease followed by phosphating in tricationic phosphate base solution to obtain a thin coating of dry film thickness (DFT) 4 micron. The polyester and epoxy-polyester powder coating of DFT 60 micron was applied by electrostatic spraying method on phosphate GI sheet referred to as system-1 and system-2, respectively. Coated panels were allowed to stand for 7 days at room temperature for curing before any testing. The microstructure and surface morphology of the coated samples were observed by a scanning electron microscope (SEM) equipped with energy dispersive spectrometry (EDX). The energy used for analysis was $15 \mathrm{KeV}$.

Corrosion resistance of the samples was evaluated by electrochemical impedance spectroscopy (EIS). The EIS measurements were carried out by using the VersaSTAT MC. A typical three-electrode system was employed in these tests. The samples acted as the working electrode $\left(1 \mathrm{~cm}^{2}\right.$ of the exposed area), saturated calomel electrode (SCE) as the reference, and graphite as counter electrode. $3.5 \% \mathrm{NaCl}$ solution was used as an electrolyte in all the measurements.

The EIS measurement was carried out in the frequency range of $100 \mathrm{KHz}$ to $0.01 \mathrm{~Hz}$, and the applied voltage was $5 \mathrm{mV}$. Salt spray tests were carried out by exposing the scribed samples $\left(6^{\prime \prime} \times 4^{\prime \prime}\right)$ in a salt spray chamber as per the ASTM B-117 test method. The panels were checked at a regular interval of time, and results were noted down in terms of blisters, creep, and red rust. The adhesion, hardness, and bond strength measurements were performed on the coated steel sample as per the ASTM D3359, ASTM D 3363, and ASTM D 4541, respectively.

\section{Results and Discussion}

3.1. Morphology. The schematic diagram of the different coating layers on the steel substrate is shown in Figure 1. The cross-sectional SEM photographs of phosphate steel with polyester powder coated and epoxy-polyester powder coated are shown in Figures 2 and 3, respectively. It can be seen that coating formed by epoxy-polyester appears to be uniform, without any surface defects and cracks. From the SEM photograph, it is clearly visible that the epoxy-polyester powder coating is highly dense, and it strongly adheres to surface, whereas some visible cracks appear on polyestercoated sheet and are not so strongly adherent to surface compared to the epoxy-polyester-coated surface.

EDX spectra of polyester powder-coated and epoxypolyester powder-coated samples are also shown in Figures 2 and 3. The peaks of different pigments materials like zinc, silica, phosphorus, and oxygen are predominant in both cases.

3.2. Bond Strength. Two major pieces of information are obtained from the bond strength test. The first is the pull-off strength, that is, bond strength of coating on substrate, and the second one is about the point where the split occurred in the paint system. The split could be an adhesive break, a cohesive break, a combination of both, or a failure of the glue.

From Table 1, cohesive failure is observed in polyester powder-coated sample, whereas adhesive failure is observed in epoxy-polyester system. Epoxy-polyester system comparatively adheres strongly with phosphated steel substrate and needs more than $5 \mathrm{MPa}$ force for any type of delamination. 


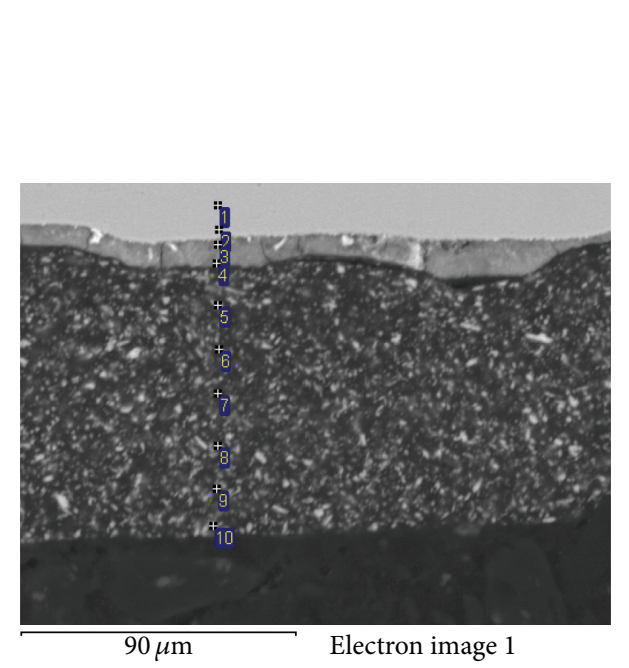

(a)

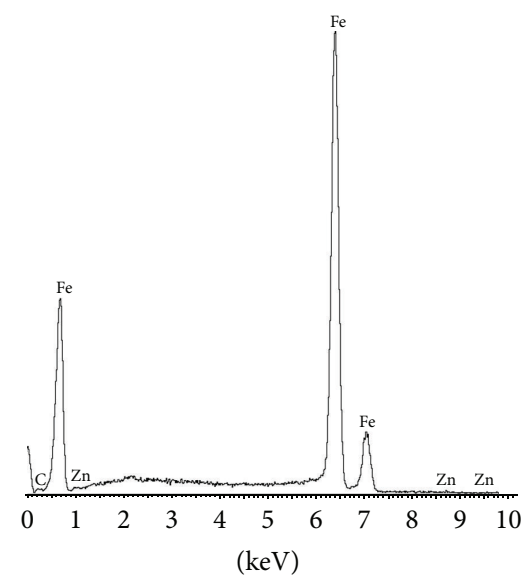

Full-scale 5718 cts cursor: -0.018 (353 cts)

Point 1

(b)

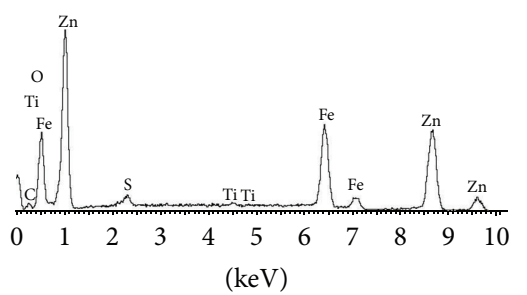

Full-scale 5718 cts cursor: -0.018 (297 cts)

Point 3

(c)

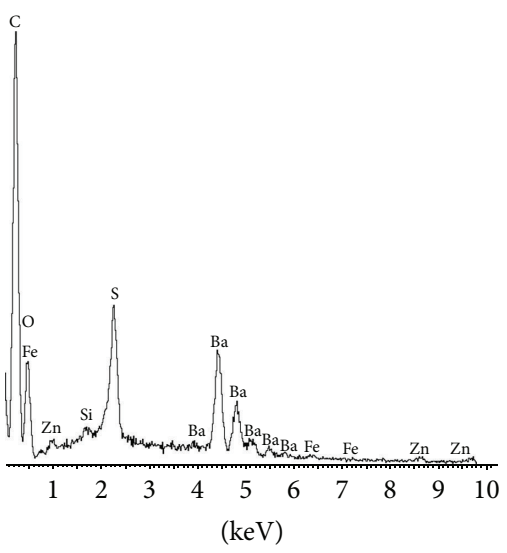

Full-scale 1613 cts cursor: 0.048 (306 cts)

Point 7

(d)

FIgURE 2: (a) Cross-sectional SEM image of polyester powder-coated sheet (system-1). (b), (c), and (d) show EDX analysis of three respective points 1,3 , and 7 , shown in (a).

The failure in the case of system-2 is from the glue itself. But polyester coating system shows failure from interface and needs only $4 \mathrm{MPa}$ force for any type of coating delamination. This improvement in system-2 is due to the formation of strong and crack-free bonding of epoxy-polyester hybrid with steel substrate, whereas polyester coating weakly adheres with the presence of internal crack, as noticed from SEM photograph and hence needs minimum force to delaminate from the surface as compared to epoxy-polyester coating [1214].

\subsection{Corrosion Resistance Property by Electrochemical} Impedance Spectroscopy. The electrochemical properties of polyester and epoxy-polyester on phosphate steel substrate were examined by EIS measurements. The main role of EIS in the characterization of an organic coating is to provide information about the properties of the protective system, such as defects, adhesion, and barrier properties, as well as to determine the onset and progression of corrosion process on metal substrate underneath the organic coating. For the EIS measurements, elements were selected through a model equivalent circuit (see Figure 4) to represents the systems under study. The systems undergo a charge transfer control according to this circuit, where $R_{\mathrm{s}}$ represents solution resistance, $R_{\mathrm{p}}$ coating resistance, $C_{\mathrm{c}}$ coating capacitance, $R_{\mathrm{ct}}$ charge transfer resistance, and $C_{\mathrm{dl}}$ double layer capacitance.

The Bode representations of the impedance data have been analyzed with VersaSTAT MC and ZSimpWin software of Princeton applied research. Single slope in the midfrequency range shows the existence of a single time constant, and the impedance data have been analyzed using the equivalent circuit.

The impedance behavior of coating system-1 and coating system- 2 on steel substrate after initial study, $144 \mathrm{~h}$, and $264 \mathrm{~h}$ 
TABLE 1: Bond strength and nature of failure of galvanised coated substrate.

\begin{tabular}{llll}
\hline System & Bond strength (in MPa) & Nature of failure & Photographs \\
\hline & 4 & Failure from top coat and adhesive & \\
\hline
\end{tabular}

TABLE 2: Impedance parameters of wash primer and epoxy primer and top coated GI in $3.5 \% \mathrm{NaCl}$ solution.

\begin{tabular}{lcc}
\hline Time, h & $\begin{array}{c}\text { System- } \\
\text { resistance }\left(\Omega / \mathrm{cm}^{2}\right)\end{array}$ & $\begin{array}{c}\text { System-2 } \\
\text { resistance }\left(\Omega / \mathrm{cm}^{2}\right)\end{array}$ \\
\hline Initial & $8.835 \times 10^{6}$ & $1.166 \times 10^{6}$ \\
$24 \mathrm{~h}$ & $7.203 \times 10^{4}$ & $1.446 \times 10^{5}$ \\
$96 \mathrm{~h}$ & 7367 & $1.185 \times 10^{5}$ \\
$144 \mathrm{~h}$ & 7166 & $1.633 \times 10^{4}$ \\
$264 \mathrm{~h}$ & 5504 & $1.576 \times 10^{4}$ \\
\hline
\end{tabular}

TABLE 3: Cross-hatch adhesion and pencil hardness results of system-1 and system-2.

\begin{tabular}{lccc}
\hline System & Cross-hatch & Percentage of area removed & Pencil hardness (at 45 $)$ \\
\hline 1 & $5 \mathrm{~B}$ & 0 & $7 \mathrm{H}$ \\
2 & $5 \mathrm{~B}$ & 0 & $9 \mathrm{H}$ \\
\hline
\end{tabular}

of immersion in 3.5\% $\mathrm{NaCl}$ solution is shown Figures 5(a)5(c) with overlay. The individual impedance behaviours with initial time, $24 \mathrm{~h}, 96 \mathrm{~h}, 144 \mathrm{~h}$, and $264 \mathrm{~h}$ are shown in Figures $6,7,8,9$, and 10 , respectively. The coating resistance and capacitance values derived from these figures are given in Table 2. It is clear from Figures 6, 7, 8, 9, and 10 and Table 2 that in the beginning of experiment, the coating resistance of polyester- and epoxy-polyester-coated samples is in the same range. Impedance of coating system-1 containing polyester powder coating shows $8.835 \times 10^{6} \Omega / \mathrm{cm}^{2}$ against the $1.166 \times$ $10^{6} \Omega / \mathrm{cm}^{2}$ resistance of coating system- 2 .

The coating resistance value of system-1 decreases from $8.835 \times 10^{6} \Omega / \mathrm{cm}^{2}$ to $5.504 \times 10^{3} \Omega / \mathrm{cm}^{2}$ after 264 h of immersion, whereas coating resistance value of system-2 decreases from $1.166 \times 10^{6} \Omega / \mathrm{cm}^{2}$ to $1.633 \times 10^{4} \Omega / \mathrm{cm}^{2}$ in $144 \mathrm{~h}$ of immersion and to $1.576 \times 10^{4} \Omega / \mathrm{cm}^{2}$ in $264 \mathrm{~h}$ of immersion. Generally, the high impedance value of polyester-coated sample shows a fast reduction in the first $24 \mathrm{~h}$ of immersion, due to the development of conductive pathways inside the film. Comparatively, a slow decrease in the impedance value was observed for the epoxy-polyester powder-coated steel sheet, followed by a small recovery after $24 \mathrm{~h}$ of immersion $[15,16]$.

Penetration of water and movement of ionic species through the coating layer may be responsible for the observed decrease in coating resistance value [17]. Other reasons could be a weaker ionic resistance and a lower-cross linking density. The dielectric constants of organic coating and water are about 6 and 80, respectively, at ambient temperature. Therefore, permeation of a small amount of water through the coating can contribute to a relatively large change in the pore resistance. It is known that diffusion of electrolyte, water, and ions through the epoxy-polyester powder-coated sample is much lower than the polyester powder-coated sample. The higher corrosion protection by epoxy-polyester powder coating on steel surface is due to the higher cross-linked density of epoxy-polyester network comparing with polyester system; in addition to high cross-linking density, the additional free hydroxyl group, that is, $-\mathrm{OH}$ of epoxy-polyester coating system (as compared to only polyester system), forms a strong bond with phosphate and steel surface. The high cross-linking density and strong adhesion of epoxy group with phosphate 


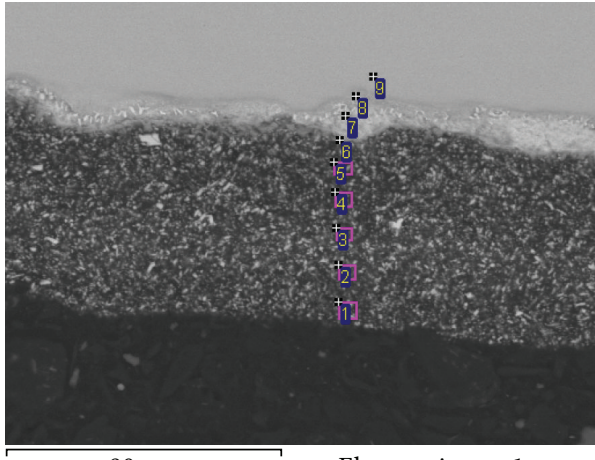

$90 \mu \mathrm{m}$
Electron image 1

(a)

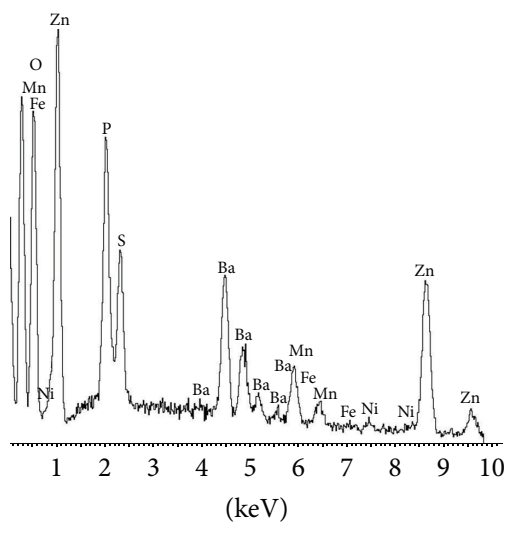

Full-scale 785 cts cursor: 0.028 (359 cts)

Point 6

(b)

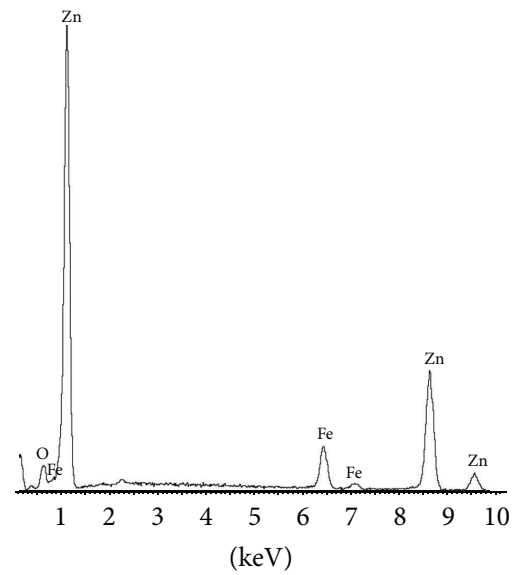

Full-scale 4830 cts cursor: 0.028 (359 cts)

Point 7

(c)

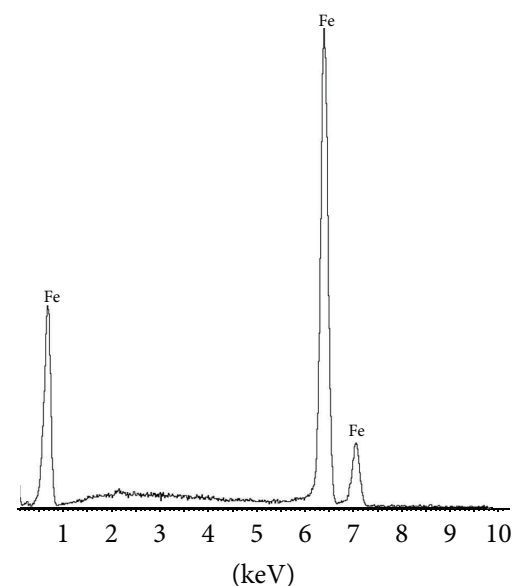

Full-scale 3118 cts cursor: 0.093 (196 cts)

Point 9

(d)

FIGURE 3: (a) Cross sectional SEM image of epoxy-polyester powder-coated sheet (system-2). (b), (c) and, (d) show EDX analysis of three respective points 6,7 , and 9 , shown in (a).

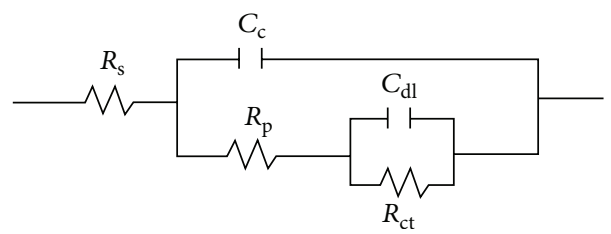

FIGURE 4: Electrical equivalent circuit for the polyester and polyester-epoxy coating on the galvanised sheet.

and steel substrate create an impermeable surface for water and other corrosive ingredients on the coated surface [18-20].

3.4. Corrosion Resistance Property by Salt Sprat Test. Performance of steel coated sheet, after $1608 \mathrm{~h}$ exposure in salt spray chamber is shown in Figure 11. It can be seen that epoxy-polyester powder-coated sample (system-2) is found to have less white rust even after $1608 \mathrm{~h}$ of exposure in salt spray chamber (ASTM B 117). Whereas coating system1 containing polyester powder coating fails after $1200 \mathrm{~h}$ of exposure in salt spray chamber (ASTM B117). There are a number of blisters in and around the edges of the scribe area in the case of system-1. 


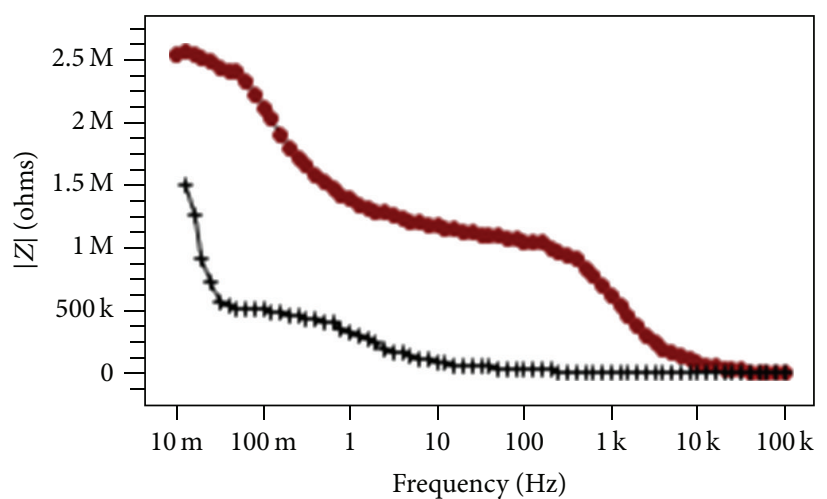

- System-1

+ System-2

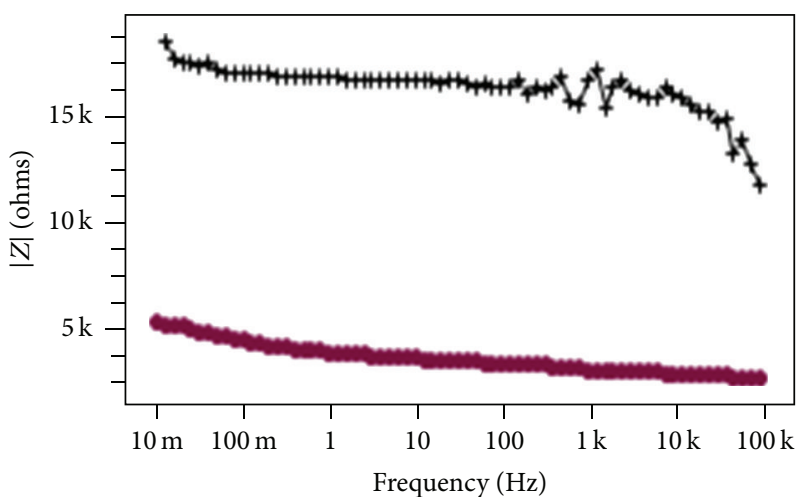

- System-1

+ System-2

(a)

(b)

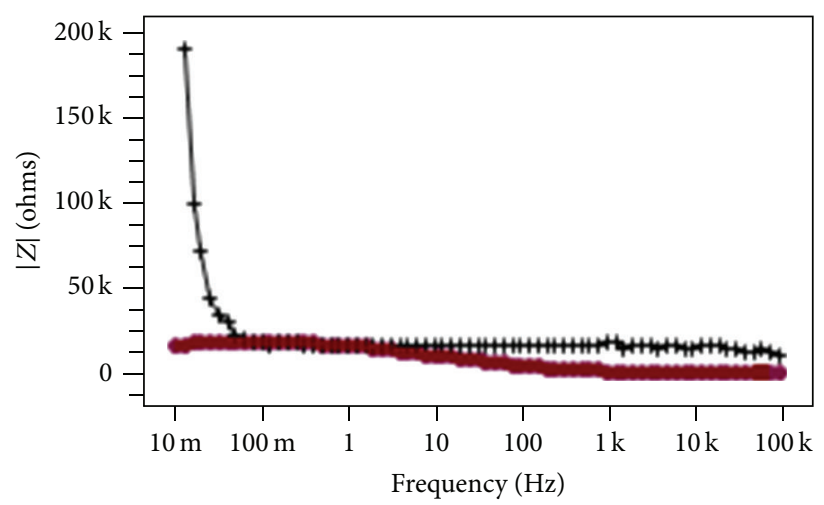

- System-1

+ System-2

(c)

Figure 5: (a), (b), and (c) show EIS overlap diagram of samples immersed for time intervals, beginning, $144 \mathrm{~h}$ and $264 \mathrm{~h}$ respectively.

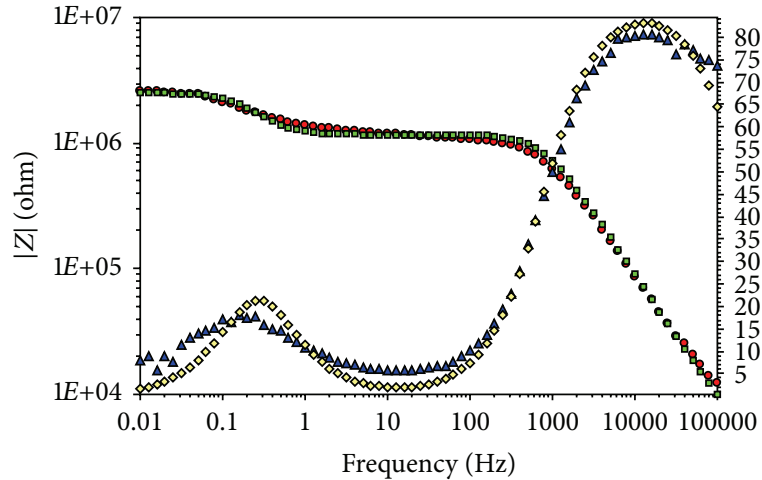

(a)

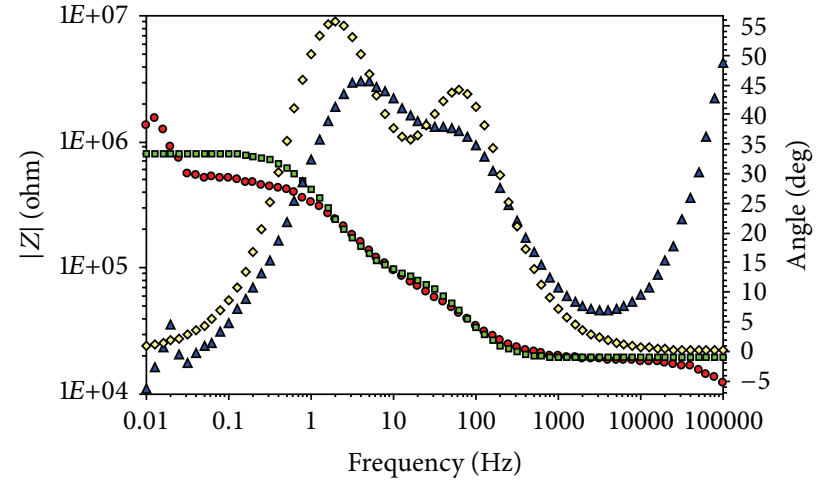

(b)

Figure 6: Bode plot of (a) system-1 and (b) system-2 at initial time.

3.5. Adhesion and Hardness. Cross hatch and pencil hardness of system-1 and system-2 were performed according to the ASTM D3359 and ASTM D3363-05. The results of these tests are shown in Table 3, which compares the adhesion and hardness properties of the two systems.
The result of the $x$-cut adhesion test was satisfactory for both the systems providing $5 \mathrm{~B}$ with no observed flaking in the cross-cut area. Therefore, no adhesion losses appeared in any interfaces. The adhesion of primer to the steel surface and the adhesion of the top coats to the primer, both were satisfactory. 


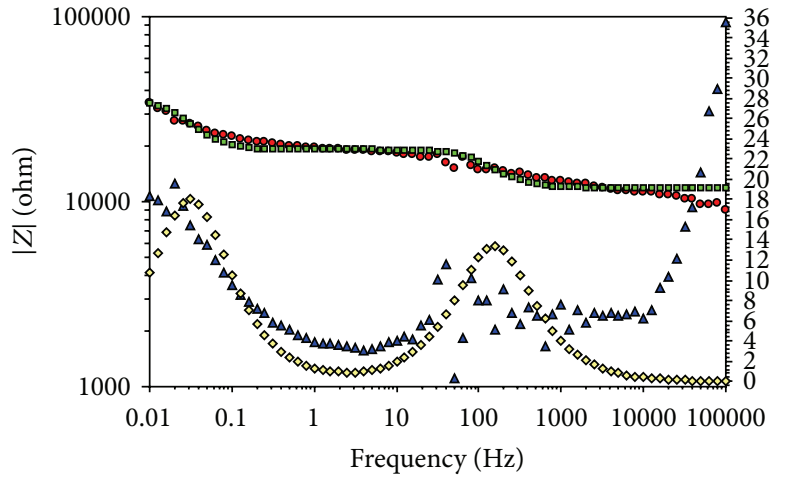

(a)

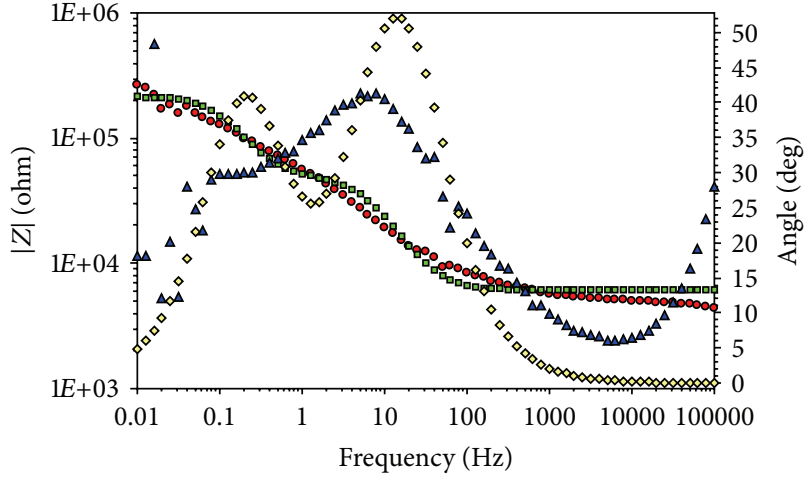

(b)

Figure 7: Bode plot of (a) system-1 and (b) system-2 at $24 \mathrm{~h}$ time.

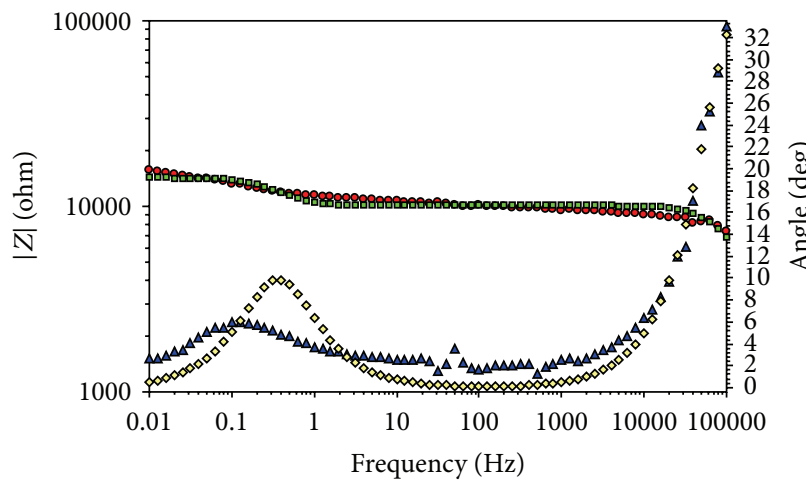

(a)

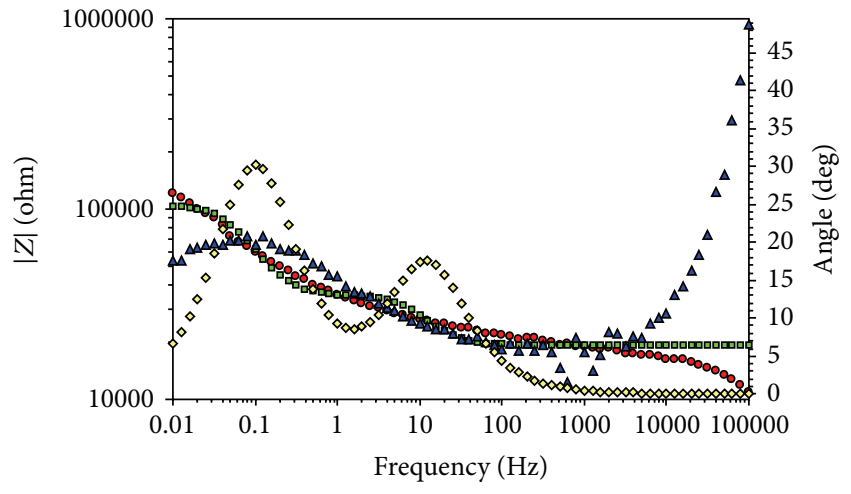

(b)

Figure 8: Bode plot of (a) system-1 (b) system-2 at $96 \mathrm{~h}$ time.

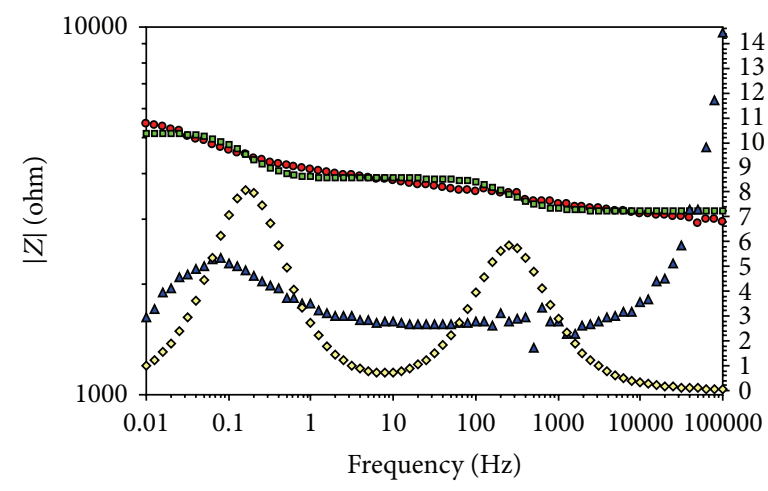

(a)

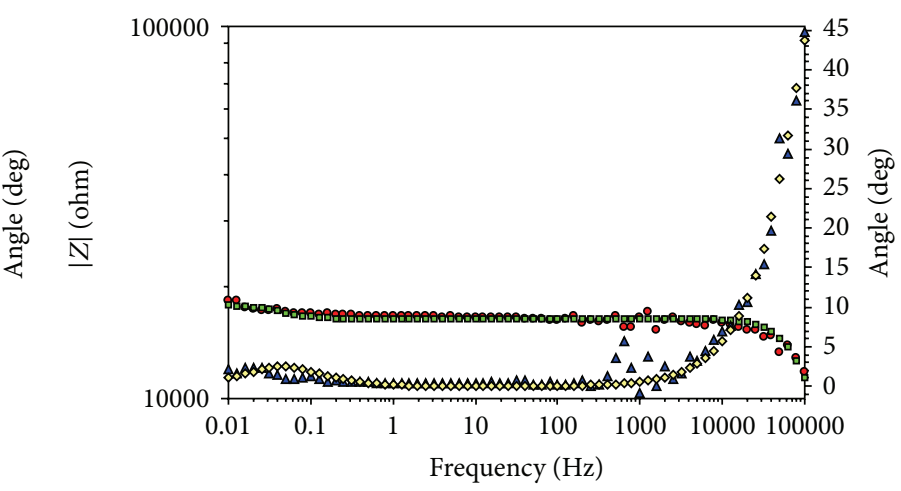

(b)

Figure 9: Bode plot of (a) system-1 and (b) system-2 at $144 \mathrm{~h}$ time.

\section{Conclusion}

The powder coatings protect galvanised steel substrates by the introduction of a barrier layer with relatively high ohmic resistance between the metallic substrate and the corrosive environment. Also, it is indicated that the cross-link density appears only to affect ionic conductivity of the film, and due to the higher cross-linked density of epoxy-polyester network comparing with polyester system, the permeability of water and ions through the coating film becomes less, and it leads to a more impervious film with a more resistant structure to corrosion. It is indicated that the polyester film is more porous due to the less cross-link density of cured polymer, compared with epoxy-polyester powder-coated samples. 


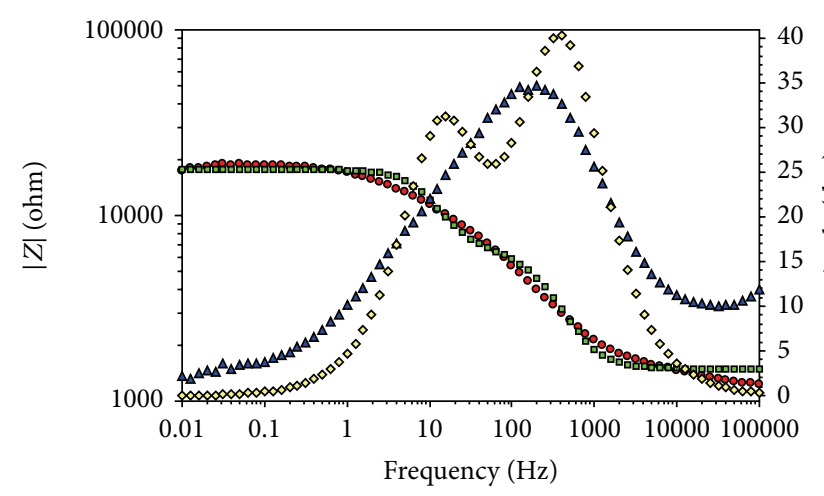

(a)

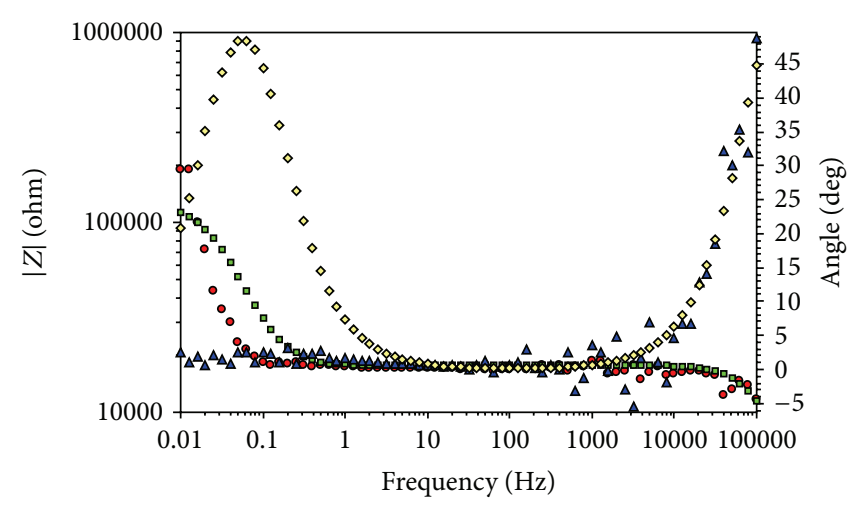

(b)

FIgUre 10: Bode plot of (a) system-1 and (b) system-2 at $264 \mathrm{~h}$ time.

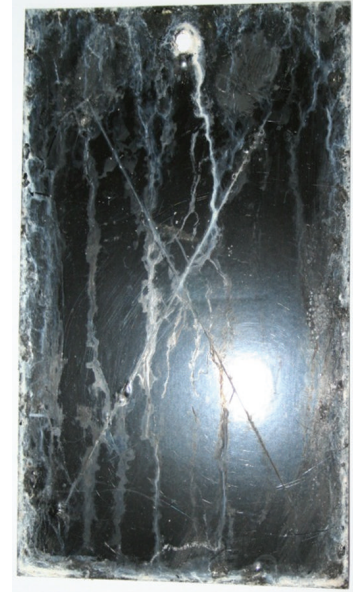

(a) System 1

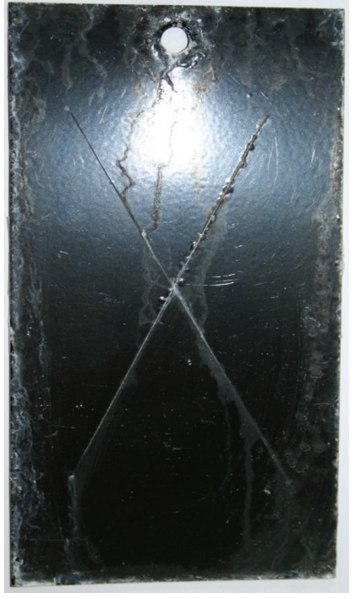

(b) System 2
FIGURE 11: Salt spray photographs of coated substrate, (a) polyestercoated sample after $1200 \mathrm{~h}$ of salt spray test, (b) epoxy-polyestercoated sample after $1608 \mathrm{~h}$ of the salt spray test.

SEM micrograph and bond strength suggest that epoxypolyester coating is more firmly adherent to the phosphate substrate than polyester coating due to more hydroxyl groups in epoxy-polyester bonding with phosphate substrate. Protective properties of fully cured organic coatings on metallic substrate may be attributed to a barrier and/or an active inhibition mechanism.

\section{Acknowledgment}

The authors would like to thank the staff of the corrosion lab for helping them during experiments.

\section{References}

[1] A. K. Guin, S. Nayak, T. K. Rout, N. Bandyopadhyay, and D. K. Sengupta, "Corrosion resistance nano-hybrid sol-gel coating on steel sheet," ISIJ International, vol. 51, no. 3, pp. 435-440, 2011.
[2] A. S. Khanna, Introduction to High Temperature Oxidation and Corrosion, ASM International, 1997.

[3] B. V. Jegdić, J. B. Bajat, J. P. Popić, and V. B. Mišković-Stanković, "Corrosion stability of polyester coatings on steel pretreated with different iron-phosphate coatings," Progress in Organic Coatings, vol. 70, no. 2-3, pp. 127-133, 2011.

[4] A. M. P. Simões, R. O. Carbonari, A. R. Di Sarli, B. del Amo, and R. Romagnoli, "An environmentally acceptable primer for galvanized steel: formulation and evaluation by SVET," Corrosion Science, vol. 53, no. 1, pp. 464-472, 2011.

[5] R. Mafi, S. M. Mirabedini, M. M. Attar, and S. Moradian, "Cure characterization of epoxy and polyester clear powder coatings using Differential Scanning Calorimetry (DSC) and Dynamic Mechanical Thermal Analysis (DMTA)," Progress in Organic Coatings, vol. 54, no. 3, pp. 164-169, 2005.

[6] D. Maetens, "Weathering degradation mechanism in polyester powder coatings," Progress in Organic Coatings, vol. 58, no. 2-3, pp. 172-179, 2007.

[7] J. B. Bajat, J. P. Popić, and V. B. Mišković-Stanković, “The influence of aluminium surface pretreatment on the corrosion stability and adhesion of powder polyester coating," Progress in Organic Coatings, vol. 69, no. 4, pp. 316-321, 2010.

[8] M. A. J. Batista, R. P. Moraes, J. C. S. Barbosa, P. C. Oliveira, and A. M. Santos, "Effect of the polyester chemical structure on the stability of polyester-melamine coatings when exposed to accelerated weathering," Progress in Organic Coatings, vol. 71, no. 3, pp. 265-273, 2011.

[9] F. L. Duivenvoorde, J. Laven, and R. Van der Linde, "Diblock copolymer dispersants in polyester powder coatings," Progress in Organic Coatings, vol. 45, no. 2-3, pp. 127-137, 2002.

[10] S. Radhakrishnan, N. Sonawane, and C. R. Siju, "Epoxy powder coatings containing polyaniline for enhanced corrosion protection," Progress in Organic Coatings, vol. 64, no. 4, pp. 383-386, 2009.

[11] V. C. Malshe and G. Waghoo, "Weathering study of epoxy paints," Progress in Organic Coatings, vol. 51, no. 4, pp. 267-272, 2004.

[12] R. Van der Linde, E. G. Belder, and D. Y. Perera, "Effect of physical aging and thermal stress on the behavior of polyester/TGIC powder coatings," Progress in Organic Coatings, vol. 40, no. 1-4, pp. 215-224, 2000.

[13] Technical Data Sheet of Ridoline 1352 BA, of M/s Henkel Chembond India Ltd. 
[14] Technical Data Sheet of Granodine, of M/s Henkel Chembond India Ltd.

[15] M. Özcan, I. Dehri, and M. Erbil, "EIS study of the effect of high levels of $\mathrm{SO}_{2}$ on the corrosion of polyester-coated galvanised steel at different relative humidities," Progress in Organic Coatings, vol. 44, no. 4, pp. 279-285, 2002.

[16] R. Naderi, M. M. Attar, and M. H. Moayed, "EIS examination of mill scale on mild steel with polyester-epoxy powder coating," Progress in Organic Coatings, vol. 50, no. 3, pp. 162-165, 2004.

[17] R. Mafi, S. M. Mirabedini, R. Naderi, and M. M. Attar, "Effect of curing characterization on the corrosion performance of polyester and polyester/epoxy powder coatings," Corrosion Science, vol. 50, no. 12, pp. 3280-3286, 2008.

[18] G. Wuzella, A. Kandelbauer, A. R. Mahendran, and A. Teischinger, "Thermochemical and isoconversional kinetic analysis of a polyester-epoxy hybrid powder coating resin for wood based panel finishing," Progress in Organic Coatings, vol. 70, no. 4, pp. 186-191, 2011.

[19] M. Barletta and A. Gisario, "An application of neural network solutions to laser assisted paint stripping process of hybrid epoxy-polyester coatings on aluminum substrates," Surface and Coatings Technology, vol. 200, no. 24, pp. 6678-6689, 2006.

[20] R. Naderi, M. M. Attar, and M. H. Moayed, "EIS examination of mill scale on mild steel with polyester-epoxy powder coating," Progress in Organic Coatings, vol. 50, no. 3, pp. 162-165, 2004. 

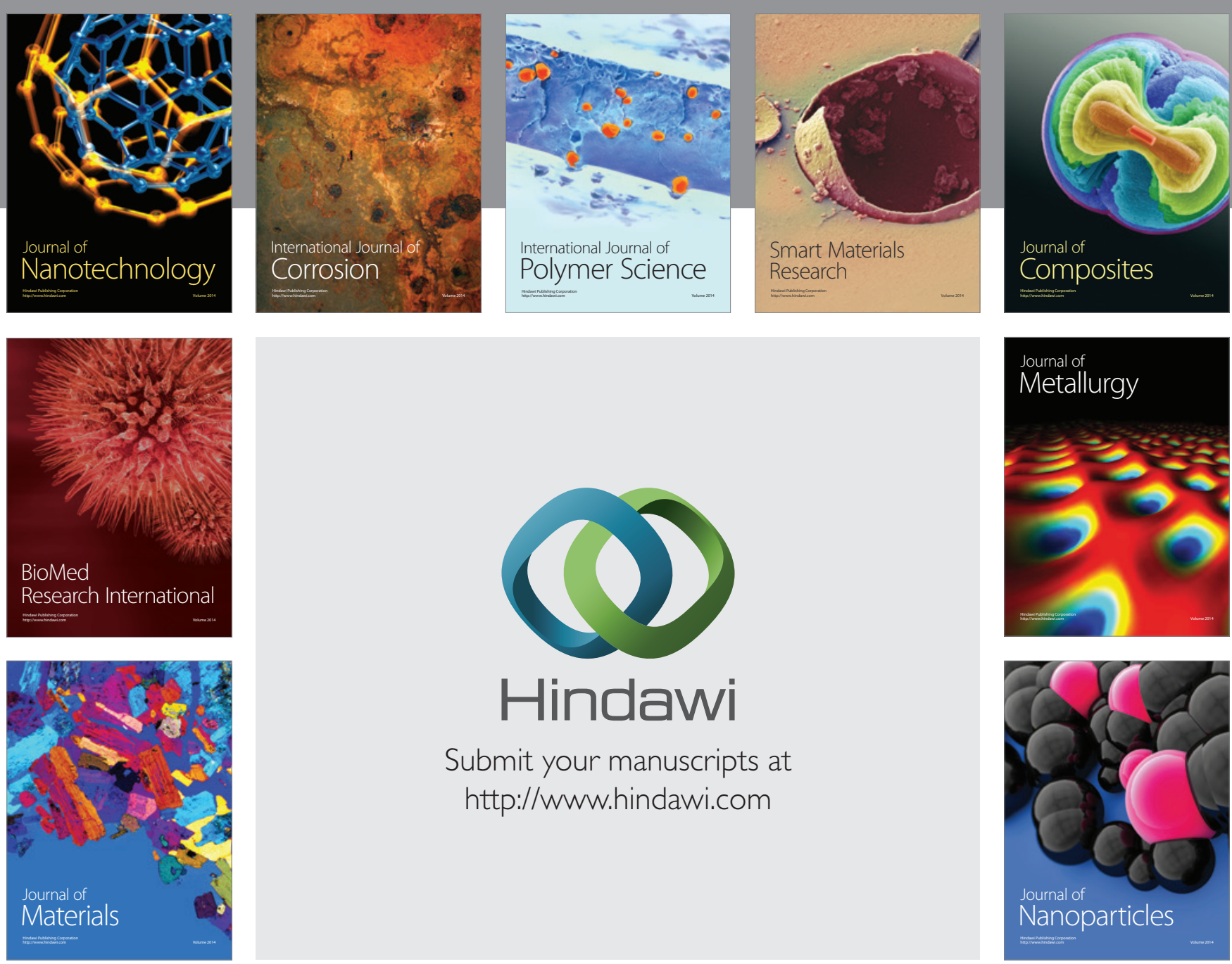

Submit your manuscripts at http://www.hindawi.com
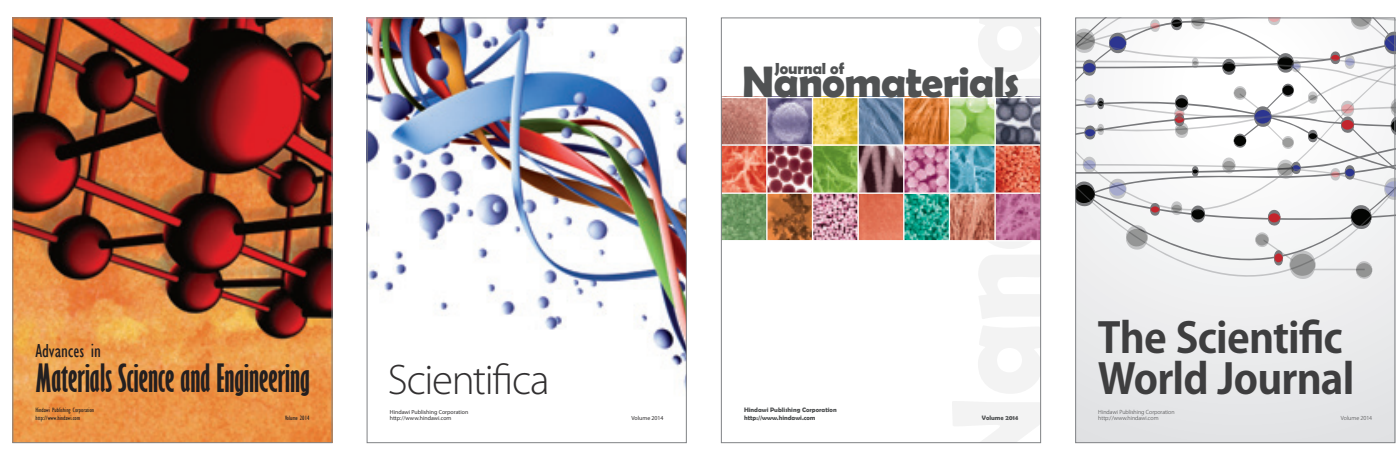

\section{The Scientific World Journal}
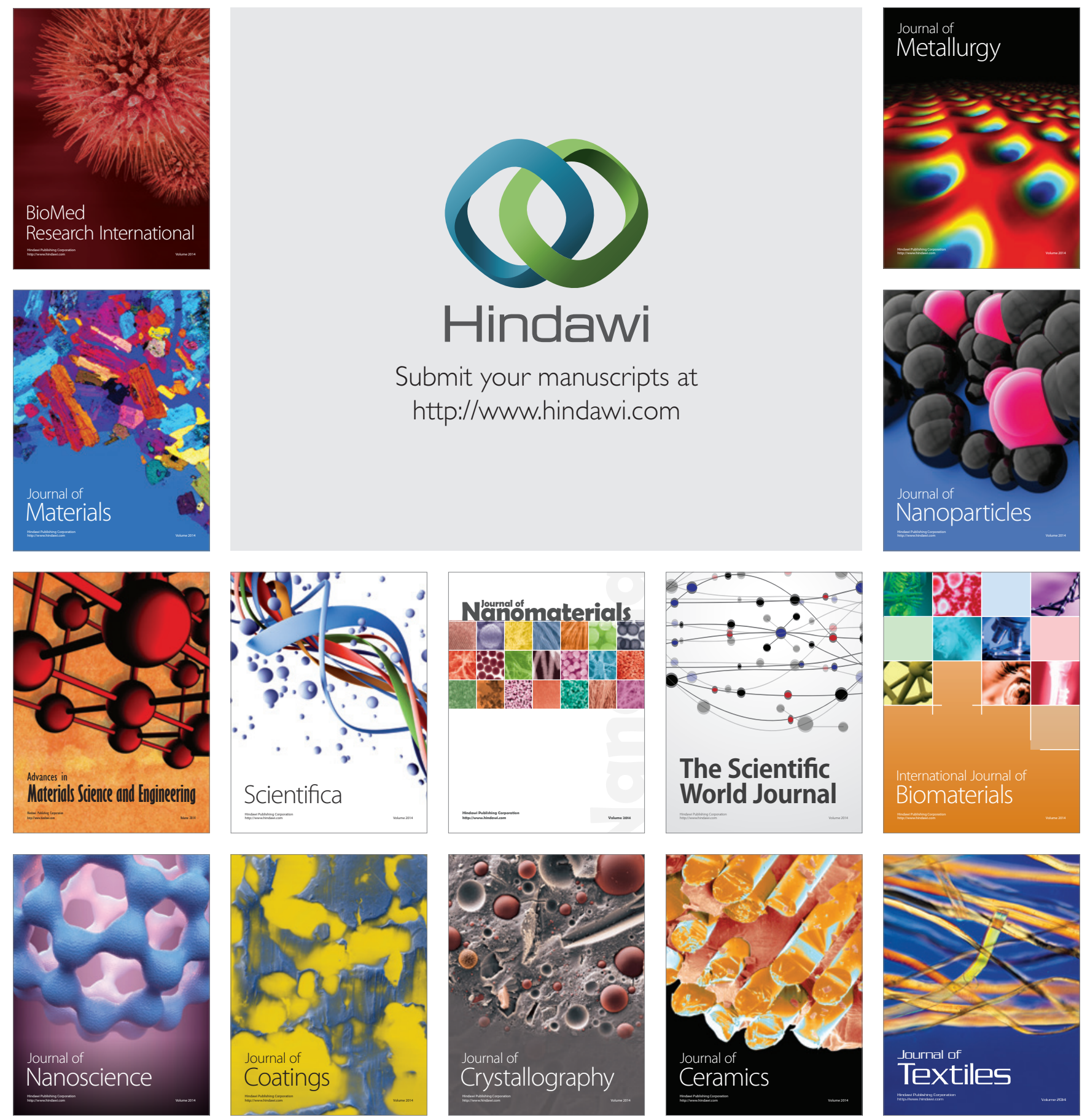